\title{
Memory processes in the identification of pitch*
}

\author{
EDWIN G. AIKEN, WILLIAM A. SHENNUM, and GARY S. THOMAS \\ Navy Personnel Research and Development Center, San Diego, California 92152
}

\begin{abstract}
A study in pitch identification with three interstimulus intervals is reported. Ss received a pretest, three drills, and a posttest. Results include: (a) superior performance on stimuli requiring only a simple discrimination judgment, (b) inferior performance at longer interstimulus intervals, (c) a greater tendency to repeat correct rather than incorrect responses to adjacent tones at the same pitch level, and (d) a modest, but reliable, improvement in pitch identification accuracy from the pre- to the posttest. Relevance of the results for an interpretation of pitch identification as dependent on memory processes is discussed.
\end{abstract}

Operationally, the distinction between a pitch discrimination and a pitch identification study comes down to the manner in which responses are related to stimuli. In pitch discrimination, two stimuli are presented in close proximity and S responds "same" or "different," or "lower," "same," or "higher." In pitch identification, a single stimulus is presented and $S$ employs a correlated response system to uniquely identify it.

Historically, discrimination has also been distinguished from identification on the basis of whether the judgment was comparative or absolute. This distinction is unfortunate, since clearly no judgment is ever absolute. In the lexicon of memory theory, it has been presumed that in a discrimination study $S$ is comparing two sensory events in short-term memory, while in an identification study a single sensory event is being referenced against some sort of longer term memory store.

In recent years, several investigators have presented data which challenge this latter distinction (Aiken, Abrams, \& Shennum, 1973; Holland \& Lockhead, 1968; Siegel, 1972; Ward \& Lockhead, 1970, 1971). Data from these studies implicate short-term memory in sensory identification performance. These investigators have shown, for example, that this kind of performance is strongly affected both by the levels of adjacent stimuli in a sequence and by responses to adjacent stimuli. One investigator (Siegel, 1972) has even asserted that the limitation on channel capacity (Miller, 1956) is really a limitation set by memory rather than by sensory processing.

If short-term memory is as important to sensory identification performance as these researchers imply, then an obvious variable to study is the time separating the single stimulus presentations, i.e., the interstimulus interval (ISI). Ever since the earliest applications of the method of absolute judgment (Wever \& Zener, 1928), investigators have typically used ISIs of less than $25 \mathrm{sec}$,

\footnotetext{
*The opinions and assertions contained herein are those of the writers and are not to be construed as official or as reflecting the views of the Navy Department or naval service.
}

and more often under $10 \mathrm{sec}$. The study here reported investigated pitch identification with ISIs of 10,30, and $60 \mathrm{sec}$. A design involving a pretest, drills, and a posttest was employed to allow assessment of the nature of any performance changes with practice.

\section{METHOD}

\section{Subjects}

Ss were 30 undergraduate students at California State University, San Diego, fulfilling an introductory psychology course requirement.

\section{Stimulus Materials}

A Hewlett-Packard audio oscillator (Model 201CR) was used to generate the pure tones, which were regulated by a Grason-Stadler electronic switch (Model 829D) and recorded on a Uher tape recorder (Model 2944). Hunter decade interval timers (Model 111B) controlled the time intervals. The stimuli were presented to the Ss over the tape recorder's internal loudspeaker at a comfortable listening level. When provided, feedback was controlled by $E$, and consisted of the illumination of a light in a labeled column of six lights at the front of the testing room. Six pure tones, separated by equal logarithmic steps, were used. They were $700,745,792,843,897$, and $954 \mathrm{~Hz}$. The stimuli were presented at either a $10-, 30-$, or $60-\mathrm{sec}$ ISI to three groups of $10 \mathrm{Ss}$ each. The six tones were arranged into two different, but equivalent, sequences of 42 tones. The two sequences were constructed to possess the following properties: equal occurrence of the six pitch levels and equal occurrence at each pitch level of trial pairs in which the same stimulus level followed itself.

\section{Procedure}

Ss were run in groups of from one to five in a small testing room. All Ss received a pretest (no feedback), three drills (with feedback), and a post test (no feedback). The two equivalent tone sequences were alternated on successive tests and drills to lessen the chance of Ss memorizing any part of a sequence. All tests and drills were given during a single session. Two minutes prior to the beginning of each test or drill, $S$ listened to a serial presentation of the six tones from lowest to highest. He was instructed that the tones were to be labeled with the digits 1 to 6 , respectively. Tonal presentations lasted $1 \mathrm{sec}$, and $S$ was allowed $5 \mathrm{sec}$ from tone off set to respond. Responses were made by penciling an $\mathrm{X}$ through the appropriate digit on an answer sheet. During drills, the correct answer light was illuminated at the end of the response period. It remained illuminated through the ISI until $2 \mathrm{sec}$ before the arrival of the next tone, the light's offset constituting a ready signal for that tone. During tests, a 
Table 1

Proportion Correct With Feedback

\begin{tabular}{ccc}
\hline $\begin{array}{c}\text { ISI } \\
(\text { Sec) }\end{array}$ & $\begin{array}{c}\text { Discrimination } \\
\text { Pairs }\end{array}$ & $\begin{array}{c}\text { Identification } \\
\text { Pairs }\end{array}$ \\
\hline 10 & .98 & .55 \\
30 & .84 & .53 \\
60 & .75 & .53 \\
\hline
\end{tabular}

2-sec ready light was illuminated $4 \sec$ before the presentation of each tone. Ss received feedback on the total number of correct identifications following all tests and drills.

\section{RESULTS AND DISCUSSION}

\section{Discrimination Responses to Adjacent Tones}

If short-term acoustic memory is involved in pitch identification, one of the first places to look for it would be in the responses to adjacent items in the sequence. It will be recalled that the item sequences had an equal number of adjacent stimuli of the same pitch for each of the six pitch levels. There were two at each level, for a total of 12 such item pairs. It should be clear that, given feedback, S's probability of correctly identifying the second member of these pairs should be heavily associated with his accuracy in retrieving the pitch of the first member from memory for comparison. (Since the feedback remained available to $S$ thoughout the ISI, there is no reason to assume that his memory for it was less than veridical.) Two other item pairs share this characteristic-those in which Pitch Level 5 was followed by Pitch Level 6, and those in which Pitch Level 2 was followed by Pitch Level 1 . If $S$ correctly judged that the second member of these pairs was higher or lower, respectively, his response to the second member was assured of being correct. There were three items of this type in the sequence, making for a total of 15 pairs in which accuracy in identifying the pitch level of the second member was limited only by S's accuracy in judging it to be higher, the same, or lower than the first member of the pair. These 15 pairs are here referred to as discrimination pairs. By contrast, the remaining pairs in the sequence required not only an accurate discrimination of higher or lower, but an additional judgment of how much. There were 26 such adjacent stimuli in the sequence, and they are here referred to as identification pairs.

Assuming a short-term memory process, performance on the second member of each pair should be better for the discrimination than for the identification pairs. Data from the three drills were combined to provide a proportion correct score for each type of pair. The scores for each $S$ were thus based on 45 discrimination and 78 identification pairs. Again, assuming a short-term memory process, a second prediction is that the advantage of discrimination items would be less, the greater the ISI (Moss, Myers, \& Filmore, 1970). Table 1 presents the data. Since the variances of the proportions proved to be homogeneous, a 3 by 2 ANOVA was carried out on them directly. The main effect of ISI was nonsignificant. The main effect of pair type was significant $(F=177.7, p<.001)$, as well as the interaction $(F=6.12, p<.01)$, confirming both predictions. Examination of Table 1 shows that the interaction is attributable to a clear effect of ISI on the accuracy of discrimination pair judgments, with no corresponding effect on identification pairs. Ss can apparently use short-term pitch memory to aid simple judgments of lower, same, or higher, but gain little when an additional judgment of amount is required. Even after $60 \mathrm{sec}$, Ss still evince considerable use of acoustic memory for the previous stimulus.

A similar analysis can be made of the pre- and posttest data where feedback was omitted. In this case, the discrimination pairs are restricted to those in which the same pitch level was repeated, while the identification pairs are all those in which a pitch-level change occurred. Without feedback, the prediction is that $S$ will employ immediate memory of the preceding stimulus to match his response change to the number of pitch levels he judges adjacent stimuli to have differed. This will be easier on discrimination pairs where the judgment of same leaves no uncertainty that the appropriate response change is zero than on identification pairs in which the judgment of different leaves uncertainty as to the extent of the response change required to match the stimulus change. It also follows that the pitch-change/response-change correspondence should decline with increasing ISI for both types of stimulus pairs. The data are presented in Table 2. The smaller the value, the better the correspondence. An ANOVA revealed relationships very similar to those found with the feedback data and in accord with a short-term memory assumption. All sources of variance were significant, i.e., ISI $(\mathrm{F}=5.19, \mathrm{p}<.025)$, pair type $(\mathrm{F}=$ $35.18, \mathrm{p}<.001)$, and their interaction $(\mathrm{F}=12.63$, $\mathrm{p}<.001$ ). Again, simple discrimination judgments were considerably aided by the contiguity of adjacent stimuli, while identification judgments were much less affected.

\section{The Contingency of Response Repetition on Response Accuracy}

Siegel (1972) has suggested a quite direct test for the presence of memory processes in categorical identification judgments. He predicts that when the same pitch level is presented on adjacent trials, with feedback, $S$ will tend to repeat his response when correct and change it to match the feedback when incorrect. On

Table 2

Difference Between Adjacent Stimulus Levels and Correlated Response Changes Without Feedback

\begin{tabular}{ccc}
\hline ISI & $\begin{array}{c}\text { Discrimination } \\
\text { Pairs }\end{array}$ & $\begin{array}{c}\text { Identification } \\
\text { Pairs }\end{array}$ \\
\hline 10 & .15 & .62 \\
30 & .48 & .77 \\
60 & .75 & .82 \\
\hline
\end{tabular}


Table 3

Proportion Response Repetition

\begin{tabular}{cccccc}
\hline \multirow{2}{*}{$\begin{array}{c}\text { ISI } \\
\text { Sec) }\end{array}$} & \multicolumn{2}{c}{ Feedback } & & \multicolumn{2}{c}{ No Feedback } \\
\cline { 2 - 3 } \cline { 6 - 6 } & Correct & Incorrect & & Correct & Incorrect \\
\hline 10 & .99 & .02 & & .96 & .89 \\
30 & .83 & .04 & & .83 & .73 \\
60 & .83 & .15 & & .62 & .54 \\
\hline
\end{tabular}

the other hand, without feedback, he predicts that $S$ will tend to repeat his response with the same probability whe ther correct or incorrect. In other words, feedback is seen as not affecting S's sensitivity to pitch levels, but rather whether he can use memory for the preceding stimulus to optimize accuracy (with feedback) or only consistency (without feedback). In the context of the present study, it would be further expected that the predicted contingency with feedback would decline at greater ISIs. The 12 repetition pairs from Drill 3 and the posttest were chosen for the analysis. The data are found in Table 3. The conditional proportions for the feedback data proved to be heterogeneous, so the ANOVA was performed on the arcsine transformations of the scores. The result was an insignificant main effect for ISI, a highly significant effect from response correctness ( $F=$ $242.9, \mathrm{p}<.001)$, and a significant interaction $(\mathrm{F}=5.45$, $\mathrm{p}<.01)$. The predicted contingency and its decline with increased ISI were confirmed. Though reduced, the contingency is still sizeable after $60 \mathrm{sec}$.

A similar analysis was performed on the no-feedback data. Examination of Table 3 shows that the contingency with response correctness is drastically reduced, the tendency to repeat the last response being very nearly as great when correct as when incorrect. The difference did, however, just reach significance $(F=$ $5.135, p<.05)$. The interaction failed to reach significance, but the main effect for ISI was reliable (F = $5.967, p<.01)$. This latter result probably reflects nothing more than a general decline in S's ability to detect that the two stimuli were the same with increasing ISI. The small, but reliable, contingency with response correctness represents the second time that two of the writers have obtained this outcome (Aiken, Abrams, \& Shennum, 1973).

A complex set of post hoc assumptions would permit this finding to be handled within the framework of signal detectability theory. However, in the context of the present experiment, the most important observation is the vastly greater contingency evidenced when feedback is provided.

\section{Perceptual Learning}

Table 4 presents the number of correct identifications on these two tests. With only 126 drill stimuli, improvement was modest, but statistically reliable ( $\mathrm{F}=$ $7.15, \mathrm{p}<.025)$. No main effect or interaction with ISI was obtained. When performance on Drill 3 is compared with the posttest, the considerable contribution of feedback to performance is seen. Summed over ISI, the mean number of correct identifications for Drill 3 and the posttest were 28.8 and 21.9 , respectively. From the standpoint of the present analysis, this difference reflects the reduced usefulness of short-term memory when the identity of the immediately preceding stimulus remains uncertain.

\section{GENERAL DISCUSSION}

It appears clear that the phrase "method of absolute judgment" as a description of the kind of study here reported is, at the very least, misleading as regards the processes involved. Data from this and other investigations have clearly tied the judgments in such studies to relational mechanisms. It would probably be wise to drop the phrase "absolute judgment" in favor of more neutral descriptions, such as "the method of categorical response" or "identification." Actually, no one has seriously contended that such judgments are absolute. The distinction has had to do with whether $\mathrm{S}$ judged a stimulus in relation to the immediate memory of a preceding stimulus, as in sensory discrimination, or in relation to some stored representation of the stimulus series, as in identification. Even this distinction is blurred, however, when it is recognized that in an identification study the stimulus on any particular trial can serve as the reference for judging the next stimulus in the sequence. Any stimulus which serves to aid identification judgments has been called an anchor, and both experimental provision of and overtraining on stimulus anchors have been shown to improve identification performance (Pollack, 1953; Cuddy, 1967). In fact, Garner (1962, p. 74) has suggested that a principal reason for the great discrepancy between the number of stimulus pairs that can be discriminated and the number of stimulus events which can be identified lies in the fact that in a discrimination experiment an anchor, i.e., the standard stimulus, is presented on every trial. The present writers interpret their data as indicating that an anchor is also present on every trial of an identification experiment, but that it is often less contiguous to the stimulus being judged and on the average carries less information.

From this point of view, it would be predicted that with two stimulus states and the same ISI, discrimination and identification performance would be equal. Another implication is that the upper limit on identification performance is, within limits, manipulable through procedural variables. Specifically, performance

Table 4

Number Correct

\begin{tabular}{ccc}
\hline $\begin{array}{c}\text { ISI } \\
(\mathrm{Sec})\end{array}$ & Pretest & Posttest \\
\hline 10 & 21.2 & 24.4 \\
30 & 18.2 & 20.4 \\
60 & 17.6 & 21.1 \\
\hline
\end{tabular}


would be expected to improve through the use of a short ISI and/or a stimulus sequence containing a high concentration of discrimination type pairs. If we attempt to eliminate these immediate memory contributions to identification performance by the use of very long ISIs and the avoidance of all discrimination type stimulus pairs, the result would be very long testing sessions and an unacceptable departure ${ }^{f_{r}}$ m randomness in the stimulus sequence, respectively. An alternative might be to interpolate some sensory $e^{-n t}$ during the ISI, which would serve to disrupt immediate memory effects without producing retroactive interference. Interpolation of a warbling tone might serve this function in a pitch-identification study.

It will be recalled that the poorer pitch-identification performance shown when feedback is absent has been interpreted by the writers as due to the reduced usefulness of immediate memory in specifying the correct response, particularly in those cases in which the same pitch level follows itself. Without feedback, memory does, however, contribute to increased response consistency. This should be kept in mind when information measures are used to index identification performance. Since information transmission rests on the consistency with which the response system is matched to the stimulus values, memory-related increases in response consistency could well be interpreted as reflecting an improved ability to identify the stimuli.

The increment in performance associated with training was modest, though statistically reliable. This outcome is common when the training is associated with a unidimensional sensory judgment. Some have argued that recognition memory in this area often shows so little improvement with practice because such stimuli are barren of meaning or associations. Although this is likely, it is also possible that training strategems have been less than optimal. It is not unreasonable to assume that as long as $\mathrm{S}$ can access memory for the immediately preceding stimulus to maintain performance, little longer term memory is likely to develop, similar to the findings on overprompting in programmed instruction (Anderson \& Faust, 1967). Training procedures which fade such immediate memory supports over drills would bear on this question. Further, Cuddy (1967) demonstrated a sizable increase in pitch recognition when training was arranged so as to increase the accuracy in identifying one of the pitches of the series. She interpreted this as indicating the use of the better acquired pitch as a reference for making relative judgments of the other stimulus levels in the series.

In any event, investigations of training strategies would appear to be a fruitful direction for research on categorical identification.

\section{REFERENCES}

Aiken, E. G., Abrams, A. J., \& Shennum, W. A. Memory effects in the method of absolute judgment: $A$ robust effect. Perceptual \& Motor Skills, $1973,36,338$.

Anderson, R. C., \& Faust, G. W. The effects of strong formal prompts in programmed instruction. American Educational Research Journal, 1967, 4, 345-352.

Cuddy, L. L. Practice effects in the absolute judgment of pitch. Journal of the Acoustical Society of America, 1967, 43, 1069-1076.

Garner, W. R. Uncertainty and structure as psychological concepts. New York: Wiley, 1962.

Holland, M. K., \& Lockhead, G. R. Sequential effects in absolute judgments of loudness. Perception \& Psychophysics, 1968, 3, 409-414.

Miller, G. A. The magical number seven, plus or minus two: Some limits on our capacity for processing information. Psychological Review, 1956, 63, 81-97.

Moss, S. M., Myers, J. L., \& Filmore, T. Short-term recognition memory of tones. Perception \& Psychophysics, 1970, 7, $369 \cdot 373$.

Pollack, I. The information in elementary auditory displays. II. Journal of the Acoustical Society of America, 1953, 25, 765-769.

Siegel, W. Memory effects in the method of absolute judgment. Journal of Experimental Psychology, 1972, 94, 121-131.

Ward, L. M., \& Lockhead, G. R. Sequential effects and memory in category judgments. Journal of Experimental Psychology. 1970, 84, 27-34.

Ward, L. M.. \& Lockhead, G. R. Response system processes in absolute judgment. Perception \& Psychophysics, 1971, 9, 73-78.

Wever, E. G., \& Zener, K. E. The method of absolute judgment in psychophysics. Psychological Review, 1928, 35, 466-493.

(Received for publication August 17, 1973; revision received December 7, 1973.) 